\title{
Enerji Tüketiminin Tarımsal Katma Değer Üzerindeki Etkisi: AB’ye Üye Geçiş Ekonomileri İçin Panel Veri Analizi
}

\section{The Effect of Energy Consumption on Agricultural Added Value: Panel Data Analysis for EU Member Transition Economies}

Mehmet Akyol ${ }^{\mathrm{a}, *}$

${ }^{a}$ Dr. Öğr. Üyesi, Gümüşhane Üniversitesi, İktisadi ve İdari Bilimler Fakültesi, İktisat Bölümü, Gümüşhane/Türkiye ORCID: 0000-0002-1173-200X

\section{MAKALE BİLGISİ}

Makale Geçmişi:

Başvuru tarihi: 27 Ekim 2019

Düzeltme tarihi: 17 Haziran 2020

Kabul tarihi: 25 Haziran 2020

Anahtar Kelimeler:

Enerji

Tarımsal üretim

Dinamik panel veri analizi

\section{ARTICLE INFO}

\section{Article history:}

Received 27 October 2019

Received in revised form 17 June 2020

Accepted 25 June 2020

\section{Keywords:}

Energy

Agricultural production

Panel data analysis
ÖZ

Enerji, yaşamsal faaliyetlerin devam ettirilmesinde önemli bir yere sahiptir. Diğer sektörlerde olduğu gibi gelişen teknoloji ile birlikte tarımsal aktivitelerin yerine getirilmesinde de enerjiden yararlanılmaktadır. Tarımsal üretimde enerji tüketiminin hızlı ve kontrolsüz artışı kimi zaman kullanılan enerjinin etkinliğinin azalmasını beraberinde getirmiştir. Bir üretim girdisi olan enerjinin etkin kullanılmaması üretim maliyetlerinin artmasına, buna karşın çıtının görece olarak azalmasına bunun sonucunda üreticilerin gelir kaybı ile karşı karşıya kalmalarına neden olmaktadır. $\mathrm{Bu}$ çalışmada tarımsal üretimde enerji kullanımının tarımsal toplam katma değer üzerindeki etkisi analiz edilmiştir. Analiz çerçevesinde $A B$ 'ye üye ve geçiş ekonomileri olarak adlandırılan 10 ülke çalışmaya dahil edilmiştir. 2009-2017 yılları arası dönemin analiz edildiği çalışmada dinamik panel veri yöntemi kullanılmıştır. Analiz sonucunda tarımsal enerji tüketiminin tarımsal katma değer üzerinde pozitif bir etkisi olduğu gözlenmiştir.

\section{A B S T R ACT}

Energy plays an important role in maintaining vital activities. Like other sectors, with the developing technology, energy is used in agricultural activities. The rapid and uncontrolled increase in energy consumption in agricultural production, has sometimes led to a decrease in the efficiency of the energy use. Inefficient use of energy, which is a production input, leads to an increase in production costs. The increase in production costs leads to a relative decrease in output and such negativities exposing producers to loss of income.. Within the framework of the analysis, 10 countries who are called as transition economies and EU member as well were included in the study. Dynamic panel data method was used in the study which analyzed the period between 20092017. As a result of the analysis, it was observed that agricultural energy consumption had a positive effect on agricultural value added.

\section{Giriş}

Tarım sektörü, nüfusun gıda ihtiyacını karşılaması ve endüstriyel üretime girdi temin etmesi bakımından stratejik bir öneme sahip olduğu için ekonomi politikalarında önemli bir konum üstlenmektedir. Tarım toplumu döneminde geçimlik ihtiyaçların karşılanması amacıyla gerçekleştirilen tarımsal faaliyetler sanayi devrimi sonrasında artan kentleşme eğilimine bağlı olarak aynı zamanda ticari bir sektör olarak gelişimini sürdürmüştür. Nitekim uluslararası ticaretin yaygınlaşması ve teknolojik ilerlemeler neticesinde ortaya çıkan makineleşme, küresel üretim sürecini hızlandırmış ve bu hızlı gelişimden tarım sektörü de payını almıştır.

Enerji, ekonomik faaliyetlerin gerçekleştirilmesinde hayati bir öneme sahiptir ve üretimin arttırılmasında en önemli itici gücü oluşturmaktadır (Faridi ve Murtaza,2013:493). Diğer sektörlerde olduğu gibi tarımsal üretimin artmasında da enerji kullanımı en az makineleşme kadar önemli bir

\footnotetext{
* Sorumlu yazar/Corresponding author

e-posta: makyol@gumushane.edu.tr
}

e-ISSN: 2149-4622. (C) 2013-2020 Muş Alparslan Üniversitesi. TÜBITTAK ULAKBİM DergiPark ev sahipliğinde. Her hakkı saklıdır. 
paya sahiptir. Enerji kullanımı ile birlikte üretim standartları yükselirken; verimlilik düzeyi, tarımsal nüfus ve sulanabilir alanların arttığı, sürdürülebilir tarımsal faaliyetlerin de hız kazandığı görülmektedir. Tarımsal üretimde enerji kullanımının belirtilen olumlu etkileri yanında; kimyasal gübre ve zirai ilaç yapımı ile makineleşmeden ötürü artan enerji tüketimi, çevre ve insan sağlığını tehdit etmeye başlamıştır (Fadavi vd:2011,88).

Geleneksel üretim süreçlerinden modern tarıma geçilmesi ticari enerji kullanımını hızlı şekilde arttırmıştır. Bu kontrolsüz artış beraberinde tarımsal üretimde kullanılan enerjinin etkinliğinin azalmasını getirmiștir (Alipour vd,2012:99). Modern tarım uygulamaları ile mal ve hizmet üretimindeki yukarı yönlü ivme neticesinde ortaya çıkan enerjiye olan bağımlılık, enerjinin uluslararası ticaretin en önemli unsurlarından biri haline gelmesine ortam hazırlamıştır (Moghaddasi ve Pour,2016:218).

Tarımda enerjinin etkin kullanımı; parasal kaynakların daha fazla tasarruf edilmesine, fosil yakıt rezervlerinin korunmasına ve çevre kirliliğinin azaltılmasına katkı yaptığı için, sürdürülebilir tarımın temel şartlarından birini oluşturmaktadır (Mohammedi, vd.,2008:3566). .Diğer yandan tarımsal enerji kullanımında etkinliğin arttırılmasında girdi miktarının azaltılarak gelirde görece olarak artış sağlamak veya çıktı düzeyini arttırmak üreticiler ve ülkeler açısından öneme sahiptir (Shrestha,2002). Ayrica tarımsal üretimde enerji maliyetleri de üretkenlik açısından büyük önem arz etmektedir. Şöyle ki ucuz enerjiye kolay ulaşım sağlayan ülkeler üretim maliyetlerini bu anlamda düşürürken enerjiye daha fazla kaynak aktarmak zorunda kalan ülkeler ise yüksek üretim maliyetleri dolayısıyla rekabet güçlerini kaybetmektedirler.

Tarımsal üretimde enerji kullanımı doğrudan ve dolaylı olmak üzere iki gruba ayrılmaktadır. Doğrudan enerji kullanımı tarımsal sahanın üretime hazırlanması, tarımsal girdi- çıktıların ve üretimi destekleyici gübre ve ilaçların taşınmasında kullanılan petrole dayalı yakıt ile çalışan araçların kullanımını ifade etmektedir. Buna ilave olarak bitkilerin kurutulması ve sulama sistemlerinin çalıştırılmasında yararlanılan doğal gaz ve elektrik kullanımı da bu gruba dahil edilmektedir (Schneph,2004). Dolaylı enerji kullanımı ise petrolün, üretim miktarını destekleyen gübre imalatında ve zararlı otlar ile mantar gibi problemlere karşı tarımsal ilaç üretiminde kullanımını ifade etmektedir (Kennedy,2000). Literatürde enerji kullanımının ekonomik büyüme üzerindeki etkisine değinen çalışmalara rastlamak mümkün iken özellikle gelișmekte olan ülkelerde enerji kullanımının tarımsal üretkenlik veya diğer bir ifade ile tarımsal katma değer üzerindeki etkisini değerlendiren pek fazla çalışma bulunmamaktadır. Her ne kadar enerji kullanımının ekonomik büyüme ve sosyal kalkınma üzerinde pozitif etkisinin olduğu bilimsel olarak kabul görmüş olsa da kırsaldaki tarımsal faaliyetlerde enerji kullanımına dair politikaların geliştirilmesinde yetersiz kalınmaktadır. Bunun en önemli nedeni ise özellikle gelişmekte olan ülkelerde hükümetlerin tarımsal üretimde verimliliğin ve katma değerin arttırılması için politika oluşturmakta pasif kalmalarıdır. Yine gelişmekte olan ülkelerde sanayileşmeye daha çok önem verilmesi, tarım sektörünün geri planda tutulmasına neden olmaktadır (Karkacier vd,2006:3796-3797).
Fuglie vd (2007) tarımsal üretimde verimliliği analiz ettikleri çalışmada 1948-2004 yılları arası dönemde ABD'de üretkenliğin tarımsal kalkınmanın lokomotifi olduğu kanısına varmışlardır. Özellikle 1980 sonrası dönemde her ne kadar sermaye, emek, kimyasallar, toprak ve enerji gibi tarımsal üretimin temel bileşenlerinde azalma meydana gelse de üretkenlikte bunun tersine artışlar yaşandığı dile getirilmektedir. Yine 1948-2004 yılları arasında yüksek verimliliğin tarımsal ürün fiyatlarındaki artışı sınırlayıcı etkiler ortaya koyduğu sonucuna ulaşılmıştır. Karkacier vd. (2006) Türkiye'de enerji tüketimi ve tarımsal üretkenlik arasındaki ilişkiyi 19712003 yılları arası dönemi kapsayan bir çalışmada değerlendirmişlerdir. Regresyon modeli sonuçları; enerji tüketimi ile tarımsal üretkenlik arasında yakın ve pozitif bir ilişki olduğunu göstermiştir. Söz konusu çalışmada ayrıca birim tarımsal alana uygulanacak yakıt vb. teşvik temelli politikaların tarımda enerji kullanımını arttırıcı etki oluşturacağ 1 ileri sürülmektedir.

Felloni vd. (1999) 83 ülke ve Çin'in 30 il ve belediyesini kapsayan çalışmada ulaşım altyapısı ve enerji tüketiminin toplam tarımsal üretim üzerindeki etkisini incelemişlerdir. Yatay kesit analizi yardımı ile yapılan analizlerden elde edilen sonuçlara göre; enerji ve ulaşım sektörlerinin toplam ürünü, tarımsal üretimin toplam verimliliğinin önemli bir değişkeni olma özelliği göstermektedir. Bir başka ifade ile ulaşım ve enerji sektörlerinin toplam ürünündeki artış tarımsal üretimin değerini arttırmaktadır. Çalışma özellikle Çin'de tarımsal verimliliğin artmasında ulaşım ve enerji sektörüne yapılacak yatırımların arttırılmasının gerekliliğini vurgulamaktadir.

Rehman ve Bashir (2015) orta gelir düzeyindeki ülkelerde enerji tüketiminin tarımsal çıktı üzerindeki etkisini 19902014 yılları arasını kapsayan dönem için ele almışlardır. Panel veri analizinin kullanıldığı çalışmada orta gelir düzeyine sahip ülkelerde enerji tüketimi ile tarımsal üretkenlik arasında pozitif ilişkinin varlığı ileri sürülmüştür. Dvoskin (1982) İsrail tarımında enerji tüketiminin önemine değindiği çalışmada toplam elektrik tüketimin yarısının tarımsal sulamada kullanıldığını belirterek enerji tasarrufu konusunda politikalar geliştirilmesi gerektiğini ve rüzgar, güneş gibi enerji kaynaklarından yararlanılmasının özellikle enerji darboğazının yaşandığı dönemlerde tarımsal ihtiyaçların karşılanmasında önemli bir boşluğu dolduracağını savunmaktadır.

Özkan vd. (2004) Türkiye'de tarım sektörünün girdi-çıktı rasyolarını kullanarak 1975-2000 yıllarını kapsayan bir çalışma ortaya koymuşlardır. Tarımsal girdi değişkenleri olarak insan ve makine, yakıt, gübre, tohum gibi insan dışı üretim faktörleri kullanılırken çıktı olarak 36 farklı tarımsal ürün kullanılmıştır. Söz konusu dönem aralığında tarımsal girdilerin yoğun enerji kullanımına bağlı olarak arttığ fakat üretim düzeyini gösteren çıktı seviyesinde bu denli bir artışın olmadığı gözlenmiştir. Girdi-çıktı rasyolarının çıktı aleyhine bozulmasının temelinde enerji kullanımında yaşanan çeşitli sorunların devam etmesi yatmaktadır. Bu bağlamda çıktı düzeyinin arttırılması için alternatif enerji kaynaklarının ve yeni teknolojilerin bulunması gerektiği ileri sürülmektedir. Diğer yandan enerji kullanımı neticesinde ortaya çıkan olumsuz etkilerin de giderilmesi adına çeşitli politikalar geliştirilmesi gerektiği önemle vurgulanan bir başka konudur. Doğal üretim kapasitesi 
dışsal enerji girdileri yardımı ile artmakta fakat sistem sürdürülebilirliğini doğal sinırlar aşıldığı için kaybetmektedir. Bahsi geçen bu ilişkiden dolayı tarımsal ekosistemde girdi-çıktı dengesinin sağlanması sistemin sürdürülebilirliğinin kapsamlı bir göstergesi olmaktadır (Zinck vd.,2002:62).

Faridi ve Murtaza (2013) 1972-2011 yılları arası dönemi kapsayan çalışmada Pakistan'da enerji tüketimi, ekonomik büyüme ve tarımsal çıktı arasında kısa ve uzun dönemde bağlantı olduğunu tespit etmişlerdir. Çalışma sonuçlarına göre özellikle elektrik enerjisinin eksikliği tarımsal çıktıyı olumsuz yönde etkilemektedir. Diğer yandan tarım sektörü haricindeki sektörlerin elektrik talebindeki hızlı artış tarım sektörünün payına düşen elektrik kullanım oranını azaltmaktadır. $\mathrm{Bu}$ nedenle tarımsal üretimde elektrik enerjisinin kullanımının yanında petrol ve doğalgaz gibi diğer enerji kaynaklarının arzının arttırılması gerektiği üzerinde önemle durulmaktadır. Raeeni vd. (2019) İran'da enerji tüketiminin tarımsal büyüme ve ihracat üzerindeki etkisini 1967-2015 dönemini kapsayan veriler yardımıyla incelemişlerdir. Ulaşılan bulgulara göre; enerji tüketiminden tarımsal büyümeye doğru tek yönlü nedensellik ilişkisinin varlığ 1 tespit edilmiş, ancak enerji tüketimi ile tarımsal ihracat arasında bir ilişki belirlenememiştir.

Enerji tüketimi ve tarımsal katma değer (verimlilik) ile ilgili çalışmalar genellikle mikro çerçevede ele alınmakta ve enerji tüketiminin çeşitli bitkisel ürünlerin üretimindeki etkisi üzerinde durmaktadır. Bu çalışmalara örnek olarak; İran'da enerji tüketiminin patates üretiminde girdi-çıktı üzerindeki etkisi Mohammedi vd. (2008), Türkiye'de kayısı üretimindeki etkisi Esengün vd. (2007), Fas’ta şeker kamışı üretimindeki etkisi Mrini vd. (2001), Malezya'da pirinç hasadına etkisi Bockari vd. (2005), ABD'de buğday üretimindeki etkisi Pringer ve Steinberg, (2008) ve Yunanistan'da pamuk üretimindeki etkisi Tsatsarelis (1991) tarafindan incelenmiştir.

Literatürdeki mevcut çalışmalar enerji tüketiminin ekonomik büyüme üzerindeki etkisi ve tarım sektröünde enerji kullanımının ürün bazında tarımsal verimliliğe etkisi üzerinde yoğunlaşmaktadır. $\mathrm{Bu}$ çalışmanın amacı literatürde yer alan birçok çalışmadan farklı olarak tarımsal üretimde kullanılan enerji tüketiminin tarımsal toplam katma değer üzerindeki etkisinin analiz edilmesidir. Analiz kapsamında geçiş ekonomileri olarak adlandırılan aynı zamanda Avrupa Birliği üyesi olan 10 ülkenin (Bulgaristan, Çek Cumhuriyeti, Hırvatistan, Macaristan, Polonya, Romanya, Slovakya, Slovenya, Letonya, Litvanya) tarım sektörü değerlendirmeye tabi tutulmuştur. Bu bağlamda söz konusu ülke grubuna dair literatürde bu denli bir çalışmanın yer almaması çalışmanın konu ile ilgili akademik yazına ve politika uygulayıcılara katk1 yapacağı düşüncesini güçlendirmektedir. 2009-2017 yılları arası dönemi kapsayan çalışmada dinamik panel veri analizinden yararlanılmıştır.

\section{Yöntem ve Uygulama}

Çalışmada kullanılan veriler Eurostat web sayfasından elde edilmiştir. Dinamik panel veri analizinin kullanıldığı çalışmada bağımlı değişken tarımsal toplam katma değer (TTKD) iken bağımsız değişkenler sırası ile tarımsal emek (TE), tarımsal enerji tüketimi (TET), tarımsal gelir
(TG)'dir. TTKD tarım sektörünün temel ve üretici fiyatları ve Euro cinsinden değerlerini ifade etmektedir. Temel fiyat, ürünlere ilişkin tüm vergilerin düşülmesi fakat üretilen tarım ürünlerine sağlanan tüm sübvansiyonlar dahil olmak üzere, üretici tarafindan belirlenen fiyatı ifade etmektedir. TE, tarım sektöründe istihdam edilen işgücünü ifade etmektedir. TET, tüm enerji alanlarında tarım sektörüne sağlanan enerji miktarını ifade etmektedir. Genellikle kgoe olarak kısaltılmış olan kilogram ham petrol değeri normalize edilmiş bir enerji birimidir. Geleneksel olarak bir kilogram ham petrolden elde edilebilecek yaklaşı enerji miktarına eşit olmakla birlikte ölçüm değeri hektar başına olarak belirlenmiştir. TG, tarım sektöründe üretim faktörlerinin elde ettiği net gelirin 2010=100 olacak şekilde endekslenmesi ile bulunan değerdir. Modelde kullanılan değişkenlerin doğal logaritmaları alınmıştır. Tablo-1 analizde kullanılan değişkenlere ait gözlem, ortalama, standart sapma (std. Sapma) en düşük (min) ve en yüksek (max) tanımlayıcı istatistikleri göstermektedir.

Tablo 1. Değişskenlere Ait Tanımlayıcı İstatistikler

\begin{tabular}{lccrll}
\hline Değişkenler & Gözlem & Ort & $\begin{array}{c}\text { Std. } \\
\text { Sapma }\end{array}$ & Min. & Max. \\
\hline TTKD & 90 & 2477.01 & 2831 & 216.39 & 10658.61 \\
TE & 90 & 492.46 & 650.8 & 43.5 & 2213.8 \\
TET & 90 & 107.30 & 67.0 & 27.75 & 267.66 \\
TG & 90 & 122.04 & 30.0 & 65.6 & 226.7 \\
\hline
\end{tabular}

Panel veri analizleri hem birim hem de zaman boyutunu dikkate alan bir analiz yöntemidir. Diğer yandan panel veri analizlerinde gözlem sayısının fazla olması parametre tahminlerinin daha güvenilir olmasına imkan sağlamaktadır. Ayrıca yine panel veri analizinde dışlanmış değişkenlere modelde yer verilmesi ile kesit veri ve zaman serilerine kıyasla daha kapsamlı modeller kurulabilmektedir (Ar1 ve Özcan:2011,108).

Dinamik panel veri modelleri iki grupta incelenebilmektedir. Bunlar dağıtılmış gecikmeli panel veri modelleri ve otoregresif panel veri modelleridir. Dağıtılmış gecikmeli panel veri modellerinde bağımsız değişkenin gecikmeli değerleri modelde bağımsız değişken olarak yer alırken otoregresif panel veri modellerinde bağıml değişkenin gecikmeli değerleri modelde bağımsız değişken olarak yer almaktadır Ekonomik birimler iktisadi karar verme aşamasında geçmişte elde edilen deneyimler ve davranış şekillerinin etkisi altında kalmaktadırlar. $\mathrm{Bu}$ açıdan iktisadi bir model tanımlanırken değişkenlerin gecikmeli değerlerinin de modele eklenmesi modelin açıklama gücünü arttırmaktadır. $\mathrm{Bu}$ bağlamda dinamik panel veri modellerinin, bağımlı ve bağımsız değişkenlerin gecikmeli değerlerini içinde barındıran modeller olarak tanımlanması mümkündür (Tatoğlu, 2013: 65).

$\mathrm{Bu}$ çalışmada genelleştirilmiş momentler yöntemi (GMM) olarak adlandırılan yöntem kullanılmıştır. Arellano ve Bond (1991) tarafindan geliştirilen bu tahmin yönteminde öncelikle birinci fark modeli araç değişken matrisi kullanılarak dönüştürülmekte ve sonrasında dönüştürülmüş model genelleştirilmiş en küçük kareler yöntemiyle tahminlenmektedir. $\mathrm{Bu}$ doğrultuda Genelleştirilmiş Momentler Tahmincisi İki Aşamalı Araç Değişkenler Tahmincisi olarak da isimlendirilmektedir (Tatoğlu, 2013: 
65). Bağımlı değişkenin gecikmeli değerinin açıklayıcı değişken olarak modele dahil edildiği dinamik modellerde ayrıca statik panel veri modellerdeki durağan olmayan kalıntı problemi de ortadan kalkmaktadır (Zeren ve Ergun,2010:77). Söz konusu dinamik panel modeli denklem1'de gösterildiği gibidir.

$Y_{i t}=\delta Y_{i, t-1}+X_{i t}^{\prime} \beta+u_{i t} i=1, \ldots, N ; t=1, \ldots, T$

Denklem 1'de $\delta$ scaler terimi, $x_{\imath t}^{\prime} 1 \times K$ ve $\beta, K \times 1$ boyutlarındaki matrisleri göstermektedir. $u_{i t}$ 'nin ise tek yönlü hata bileşen modelini izlediği varsayılmaktadır. (Baltagi, 2005: 135).

$u_{i t}=\mu_{i}+v_{i t}$

Denklem 2'de $\mu_{i} \sim \operatorname{IID}\left(0, \sigma_{u}^{2}\right)$ ve $v_{i t} \sim \operatorname{IID}\left(0, \sigma_{v}^{2}\right)$ kendi aralarında ve birbirlerinden bağımsız hata terimleridir. Denklem 1'de bağımlı değişkenin gecikmeli değeri $\left(Y_{i, t-1}\right)$ hata terimi $\left(u_{i, t-1}\right)$ ile korelasyonludur. Buna ek olarak $Y_{i t}, \mu_{i}$ 'nin bir fonksiyonu olduğundan $Y_{i, t-1}$ de $\mu_{i}$ 'nin bir fonksiyonudur. $\mathrm{Bu}$ nedenle $Y_{i, t-1}$, ayn 1 zamanda $u_{i}$ ile korelasyonlu olmaktadır (Baltagi, 2005:135). Bağımlı değişken ile hata terimi arasındaki korelasyonun giderilmesi gerekmektedir. Diğer yandan sabit etki ve rassal etki modellerinde de bağımlı değişken kullanımına paralel olarak gecikmeli bağımlı değişkenin hata terimi ile arasındaki korelasyon ilişkisi önemli sorunlar ortaya koymaktadır (Arı ve Özcan:2011,108).

$\mathrm{Bu}$ anlamda Balestra ve Nerlove (1966: 603) gecikmeli bağımlı değişkenin kalıntılar ile korelasyonlu olması en küçük kareler yöntemi ile tahmini tutarsız hale getirdiğini iler sürmektedir. En küçük kareler yönteminde modelin içsel değişkenlerinden biri bağımlı değişken olarak modele katıldığında ve diğer içsel değişkenler bağımsız değişken olarak yorumlandığında bağımsız olarak kabul edilen içsel değişkenler ile denklemin kalıntıları arasındaki korelasyon nedeniyle sonuçlar tutarsızdır. Kalıntılar ile korelasyon sergileyen bağımlı değişken yerine uygun bir araç değişken kullanılmalıdır.

Yine Balestra ve Nerlove (1966) bağımsız değişkenin gecikmeli değerlerinin araç değişken olarak kullanılmasını önermişlerdir. $\mathrm{Bu}$ tahminci dinamik modelde ortaya çıkan sapmayı azaltsa da birim ve zaman etkinin varlığını göz ardı ettiğinden sapmalı sonuçlar vermektedir (Tatoğlu, 2013: 67-68). Bu nedenle Anderson ve Hsiao (1981) birim etkiden kurtulmak adına birinci farkların alınması gerektiğini ileri sürmektedirler. Bu bağlamda $\Delta \mathrm{y}_{\mathrm{i}, \mathrm{t}-2}=\left(\mathrm{y}_{\mathrm{i}, \mathrm{t}-2}\right.$ $\left.-\mathrm{y}_{\mathrm{i}, \mathrm{t}-3}\right)$ veya genel olarak $\mathrm{y}_{\mathrm{i}, \mathrm{t}-2}$ ' $\mathrm{yi} \quad \Delta \mathrm{y}_{\mathrm{i}, \mathrm{t}-1}=\left(\mathrm{y}_{\mathrm{i}, \mathrm{t}-1}-\mathrm{y}_{\mathrm{i}, \mathrm{t}-2}\right)$ in araç değişkeni olarak kullanmayı önermişlerdir. Söz konusu araç değişkenler aynı zamanda $\Delta v_{i, t}=v_{i, t}-v_{i, t-1}$, ile korelasyonlu olmayacaktır. Kullanılacak araç değişkenler, açıklayıcı değişkenlerle korelasyon içerisinde iken hata terimi ile korelasyonsuz olması gerekmektedir. Ancak dinamik panel modelin tahmini için önerilen araç değişken tahmin yöntemi, moment koşullarının tamamının kullanımına izin vermediğinden ve $\Delta v_{\text {it }}$ yapısını dikkate almadığından, tutarlı ancak etkin olmayacaktır (Arı ve Özcan:2011,109).

Yukarıda bahsi geçen olumsuzluklardan ve tahmin sonuçlarının tutarsız olmasından dolayı Arellano ve Bond (1991) genelleştirilmiş momentler (GMM) tahmincisinin kullanımını önermişlerdir. Söz konusu tahmin yöntemi birinci fark modelini kullanan tahmincilerden biridir. $\mathrm{Bu}$ yöntem araç değişken matrisi ile birinci fark modelini dönüştürerek Genelleştirilmiş En Küçük kareler yöntemi ile tahmin etmektedir (Tatoğlu, 2012: 67-80). Bağımlı değişkenin gecikmeli değerinden başka açıklayıcı değişkeni olmayan model, denklem 3 teki gibi yazılmaktadır (Baltagi, 2005: 137).

$Y_{i t}=\delta y_{i, t-1}+u_{i, t} \quad u_{i t}=\mu_{i}+v_{i}$

$\mathrm{i}=1, \ldots, \mathrm{N} ; \mathrm{t}=1, \ldots, \mathrm{T}$

Modelin birinci fark1;

$Y_{i t}-Y_{i, t-1}=\delta\left(Y_{i, t-1}-Y_{i, t-2}\right)+\left(v_{i t}-v_{i, t-1}\right)$

şeklinde yazılmaktadır. $\mathrm{Bu}$ şekilde birim etki modelden elimine edilmiştir. Ayrıca $\left(v_{i t}-v_{i, t-1}\right)$ MA (1) birim köklüdür. Modelde $\left(y_{i t}-y_{i, t-2}\right)$ için geçerli olan araç değişkenler gecikmeli değerler olmaktadır. Örneğin $\mathrm{T}=3$ için $y_{\mathrm{i} 3}-\mathrm{y}_{\mathrm{i} 2}=\delta\left(\mathrm{y}_{\mathrm{i} 2}-\mathrm{y}_{\mathrm{i} 1}\right)+\left(\mathrm{v}_{\mathrm{i} 3}-\mathrm{v}_{\mathrm{i} 2}\right)$. Burada $\mathrm{y}_{\mathrm{i} 1}$ geçerli araç değişken olmakla birlikte $\quad\left(y_{i 2}-y_{i 1}\right)$ ile yüksek korelasyonlu ve $\left(v_{\mathrm{i} 3}-v_{\mathrm{i} 2}\right)$ ile korelasyonsuzdur (Baltagi, 2005: 137). $v_{i t}$ otokorelasyonsuz olduğu sürece $y_{i 1}$ uygun bir araç değişken olacaktır.

Arellano ve Bond (1991) tarafindan uygulanan genelleştirilmiş momentler tahmincisi ile birinci fark dönüşümü ile sabit parametre modelden düşmekte bağımlı değişkenin bir gecikmeli değişkeni modeldeki bağımsız değişkenler ile birlikte modele bağımsız değişken şeklinde dahil edilerek bir aşamalı tahmin yapılmaktadır. Diğer yandan Arellano ve Bond (1991:283) aşırı tanımlama kısıtlamalarının geçerli olup olmadığını sargan testi ile kontrol etmektedirler. Sargan testi aşağıdaki şekilde ifade edilmektedir (Baltagi, 2005:141).

$m=\Delta \hat{v} W\left(\sum_{i=1}^{N} W_{i}^{\prime} \Delta \widehat{(v)}_{i} \widehat{(v)}_{i}^{\prime} W_{i}\right)^{-1} W^{\prime} \Delta \hat{u} \sim \chi_{p-K-1}^{2}$

(5)

Denklem 5'de $\mathrm{p} \mathrm{W}$ nin sütun sayısını ifade ederken $\Delta \hat{v}$ iki aşamalı tahminden elde edilen kalıntıları göstermektedir. $W_{i}=\operatorname{diag}\left(Y_{i 1}, \ldots, Y_{i m}\right),(m=1, \ldots, T-2$ eşitliği vardır. $\mathrm{s}$ test istatistiği p-K-1 serbestlik derecesinde $\chi^{2}$ dağılmaktadır (Tatoğlu, 2012:99). Genel olarak panel veri modeli aşağıdaki şekilde yazıldığında;

$$
Y_{i t}=\alpha \gamma_{(i t-1)}+\beta^{\prime} x^{*}{ }_{i t}+\mu_{i}+\mathrm{v}_{i t}=\delta^{\prime} x_{i t}+\mu_{i}+v_{i t}
$$

Modelde $v_{i t}$ otokorelasyonsuz iken $x^{*}{ }_{i t}, \quad \mu_{\mathrm{i}}$ ile korelasyonludur. Birinci farklar modelinde birinci mertebeden otokorelasyon olması $\mathrm{E}\left(\mathrm{v}_{\mathrm{it}} \mathrm{V}_{\mathrm{i}(\mathrm{t}-1)}=0\right.$ olması önemli değildir. GMM tahmincisinin etkin olması için ikinci mertebeden otokorelasyon olmaması $\left(E\left(v_{i t} v_{i t-2}=\right.\right.$ $0)$ gerekmektedir. Arellona ve Bond (1991) okorelasyonu test etmek için birinci farklar modelinden elde edilen kalıntıları kullanmaktadır. $\mathrm{H}_{0}$ hipotezi "otokorelasyon yoktur” şeklindedir (Arellano ve Bond,1991:280-281).

$m_{2}=\frac{\hat{v}_{-2} \hat{v}}{\hat{v}^{1 / 2}} \tilde{a} N(0,1)$

Denklem 6'da Arellona ve Bond (1991) test istatistiğini göstermektedir. İkinci mertebeden otokorelasyonun varlığının testi için birinci farklar modelinin sonuçlarından çıkarılan kalıntılar kullanılmaktadır (Arellano ve Bond,1991:280-281). Denklemde $\hat{v}_{-2}$ iki kez gecikmesi alınmış kalıntıların vektörüdür. Temel hipotezin kabul 
edilmesi hata teriminin $\left(v_{i t}\right)$ otokorelasyonsuz olduğu anlamına gelmektedir (Tatoğlu, 2012: 101).

Dinamik panel veri analizi çerçevesinde fark GMM yaklaşımına göre, tarımsal enerji tüketiminin tarımsal toplam katma değer üzerindeki etkisini analiz etmek üzere kurulan model aşağıdaki gibidir;

$\operatorname{LTTK}_{i t}=\alpha_{t}+\beta_{1} \operatorname{LTTK}_{(i t-1)}+\beta_{2} L T E_{i t}+\beta_{3} L T E T_{i t}+$ $\beta_{4} L T G_{i t}+\mathrm{yi}+\mathrm{yt}+\mathrm{vit}$

Denklem 7'de $y_{i}$, gözlenemeyen bireysel etkileri; $y_{t}$ gözlenemeyen zamana özgü etkileri; $v_{\text {it }}$ hata terimi bileşenlerini; L, ilgili değişkenin logaritmasının alındığını ifade etmektedir. Ayrıca $y_{i}$ ile $y_{t}$ 'nin sabit olduğu varsayılmaktadır.

\section{Bulgular}

Model sonuçlarına göre tarımsal toplam emekte (TE) meydana gelen \%1 lik bir artış tarımsal toplam katma değer üzerinde (TTKD) pozitif bir etkiye sahip olmakla birlikte $\% 0.22$ lik bir artış sağlamaktadır. Diğer yandan yine tarımsal toplam gelirde (TG) meydana gelen \%1 düzeyindeki bir artış tarımsal toplam katma değer (TTKD) üzerinde pozitif etkiye sahip ve \% 1.10 düzeyinde artış sağlamaktadır. Son olarak tarımsal enerji tüketiminde (TET) meydana gelen \%1'lik artış toplam tarımsal katma değeri pozitif yönde ve $\% 0.97$ düzeyinde etkilemektedir. Modelin bütününün anlamlılık derecesini ölçmek için yapılan Wald testi sonuçlarına bakıldığında genel olarak model anlamlıdır sonucu çıkmaktadır. Tablo-2'de GMM analiz sonuçları verilmektedir.

Tablo 2. Modele Ait GMM Analiz Sonuçları

\begin{tabular}{|c|c|c|c|}
\hline \multicolumn{4}{|c|}{ Bağımlı Değişken: TTKD } \\
\hline $\begin{array}{l}\text { Bağımsız } \\
\text { Değişkenler }\end{array}$ & Katsayı & Test istatistiği & $\begin{array}{l}\text { P-Olasılık } \\
\text { Değeri }\end{array}$ \\
\hline LTTKD (1) & $0.123^{* *}$ & 1.99 & 0.047 \\
\hline LTE & $0.223 * * *$ & 1.75 & 0.081 \\
\hline LTET & $0.971 *$ & 10.91 & 0.000 \\
\hline LTG & $1.096^{*}$ & 5.58 & 0.000 \\
\hline Diğer Testler & & Test istatistiği & $\begin{array}{l}\text { P-Olasilık } \\
\text { Değeri }\end{array}$ \\
\hline Wald Testi $\left(\chi^{2}\right)$ & & 216.86 & 0.000 \\
\hline Sargan Testi & & 27.72 & 0.425 \\
\hline $\begin{array}{l}\text { Arellano-Bond } \\
\text { Testi AR(1) }\end{array}$ & Otokorelasyon & -0.625 & 0.531 \\
\hline $\begin{array}{l}\text { Arellano-Bond } \\
\text { Testi AR(2) }\end{array}$ & Otokorelasyon & -0.528 & 0.597 \\
\hline
\end{tabular}

$*, * *, * * *$ sirasıyla $\% 1, \% 5$ ve $\% 10$ düzeyinde istatistiksel olarak anlamlılı̆̆ göstermektedir.

Diğer yandan tablonun alt kısmında otokorelasyonun varlığını test etmek amaciyla Arellano ve Bond tarafindan önerilen otokorelasyon testi sonuçları gözlenmektedir. Bilindiği üzere otokorelasyon testi $\mathrm{H}_{0}$ hipotezi otokorelasyon yoktur şeklinde kurulmaktadır. Daha önce de değinildiği üzere birinci ve ikinci mertebeden otokorelasyonun test edilmesi gerekmektedir. Birinci mertebeden otokorelasyonun olması önemli görülmemekle birlikte ikinci mertebeden otokorelasyon olmaması önem arz etmektedir. Tablo-2 de görüldüğü üzere model, hem 1 . hem de 2. mertebeden otokorelasyon barındirmamaktadır. Bir başka ifade ile H0 hipotezi reddedilememekte ve otokorelasyonun olmadığı anlaşılmaktadır.

Son olarak Sargan testi sonuçları da modelde aşırı tanımlama kısıtlarının geçerliliğini yani bir başka ifade ile kullanılan araçların geçerliliğini test etmektedir. Aşırı tanımlama kısıtlamaları geçerlidir şeklinde kurulan $\mathrm{H} 0$ hipotezi Sargan testi sonucuna göre reddedilememektedir Test sonucu aşırı tanımlama kısıtlarının geçerli olduğunu diğer bir ifade ile kullanılan araçların geçerli olduğunu ifade etmektedir. Son olarak test istatistiği p-k-1 (90-3-1) serbestlik derecesi ve $\chi 2$ dağılımına uymaktadır.

\section{Sonuc}

Tarım sektörü ülke ekonomilerine sağladığı doğrudan ve dolaylı katkı ile önemli bir yere sahiptir. Özellikle sanayi sektörüne hammadde ve sermaye sağlaması, nüfusun gida ihtiyacının karşılanması, ihracat yolu ile ülkeye döviz girdisi sağlaması ve stratejik öneme sahip olması gibi özellikleri tarım sektörünü vazgeçilmez kılmaktadır. Teknolojinin gelişmesi ile birlikte tarımsal üretim süreçlerinde meydana gelen gelişmeler ve makine kullanımının yaygınlaşması enerji kullanımını gündeme getirmiştir. Tarımsal üretimde enerji kullanımı ile birlikte tarımsal üretim miktarı ve verimlilik arttırılmaya çalışılmıştır. Her ne kadar yukarıda bahsi geçen hedeflere ulaşılması anlamında tarımsal üretimde enerji kullanımının arttırılmaya çalışılması aşırı enerji tüketimini beraberinde getirmiş olsa da enerji maliyetlerinin her geçen gün artması tarımsal üretimde aşırı tüketim dolayısı ile üretimin maliyetini arttırmakta ve neticede tarımsal verimlilik azalmaktadir.

$\mathrm{Bu}$ çalışmada tarımsal enerji tüketiminin tarımsal katma değer üzerindeki etkisi analiz edilmiştir. Panel veri metodunun kullanıldığı analizde tarımsal enerji tüketiminde meydana gelen artış tarımsal katma değeri pozitif yönde etkilemektedir. Diğer yandan yine tarımsal emeğin ve tarımsal gelirin artması aynı şekilde tarımsal katma değeri pozitif yönde etkilemektedir. Çalışma sonuçları değerlendirildiğinde önemli bir tarımsal girdi bileşeni olan enerjinin etkin ve verimli kullanılması tarımsal üretimi arttırırken tarımsal katma değere de pozitif etkiler yapacağ gözlenmektedir. Ayrıca elde edilen bulgular literatürde bu alanda yapılan çalışma sonuçlarıyla (Karkacier vd.2006; Felloni vd. 1999; Rehman ve Bashir, 2015; Faridi ve Murtaza,2013) paralellik göstermektedir. $\mathrm{Bu}$ bağlamda özellikle tarım sektörüne yönelik enerji yatırımlarının arttırılması ve sektörde kullanılacak enerjinin kullanım maliyetlerinin azaltılmasına yönelik politikaların geliştirilmesi gerekmektedir. Söz konusu politikaların hayata geçirilmesi bir yandan ülke ekonomilerine pozitif katkı sağlarken diğer yandan tarımsal gelirin arttırılması yolu ile bölgesel ve ulusal kalkınma çabalarına ivme kazandiracaktır. 


\section{Kaynakça}

Alipour, A., Veisi, H., Darijani F., Mirbagheri, M. \& Behbahani A.G. (2012). Study and Determination of Energy Consumption to Produce Conventional Rice of The Guilan Province, Res. Agr. Eng, 58 (3): 99106.

Arellano, M. \& Bond, S. (1991). Some Tests of Specification for Panel Data: Monte Carlo Evidence and an Application to Employment Equations, The Review of Economic Studies, 58(2), 277-297.

Arı, A. \& Özcan, B. (2011). İşçi Gelirleri ve Ekonomik Büyüme İlişkisi: Dinamik Panel Veri Analizi, Erciyes Üniversitesi İktisadi ve İdari Bilimler Fakültesi Dergisi, (38), 101-117.

Balestra, P. and Nerlove, M. (1966). Pooling CrossSection and Time Series Data in the Estimation of a Dynamic Model: The Demand for Natural Gas, Econometrica (34), 585-612.

Baltagi, B. (2005). Econometric Analysis of Panel Data. John Wiley \& Sons

Bockari-Gevao, SM., Wan, I., WI., Azmi, Y. \& CW. (2005). Analysis of Energy Consumption in Lowland Rice-Based Cropping System of Malaysia. Sci Technol, 27(4):819-826.

Dvoskin, D. (1982). Energy - Dependent Agriculture in Israel, Energy in Agriculture, 1:131 - 139.

Esengun K, Gunduz O. \& Erdal G. (2007). Input-Output Energy Analysis in Dry Apricot Production of Turkey. Energy Convers Manage, 48:592-598

Fadavi, R.,Keyhani, A. \& Mohtasebi, S.S. (2011). An Analysis of Energy Use, Input Costs and Relation Between Energy Inputs and Yield of Apple Orchard, Res. Agr. Eng., 57(3): 88-96

Faridi, M. Z. \& Murtaza, G. (2013). Disaggregate Energy Consumption, Agricultural Output and Economic Growth in Pakistan, The Pakistan Development Review, 52(4):493-516

Felloni, F., Thomas, I.W. \& Wandschneider, P. (1999). Evidence of The Effect of Infrastructure on Agricultural Production and Productivity: Implications for China. In: Wahl, T.I., Fuller, F. (Eds.), Chinese Agriculture and the WTO. Impact Center, Washington State University, Pullman

Fuglie, K., MacDonald, O., James M. \& Ball, E. (2007). Productivity Growth in U.S. Agriculture, United States Department of Agriculture Economic Research Service, Economıc Brief, No. 9.Raaeni, A. A. G., Hosseini, S. \& Moghaddasi, R. 2019. How Energy Consumption is Related to Agricultural Growth And Export: an Econometric Analysis on Iranian Data, Energy Reports, 5:50-53.
Karkacier O., Goktolga G. \& Cicek A., 2006. A Regression Analysis of The Effect of Energy Use in Agriculture, Energy Policy, (34), 3796-3800.

Kennedy, S. (2000). Energy Use in American Agriculture, Sustainable Energy Term Paper 5/1/00 erişim:20.09.2019

http://web.mit.edu/10.391J/www/proceedings/Agric ulture_Kennedy2000.pdf,

Moghaddasi R. \& Pour. A.A. (2016). Energy Consumption and Total Factor Productivity Growth in Iranian Agriculture, Energy Reports, (2), 218-220.

Mohammedi, A., Tabatabaeefar, A., Shahin S., Rafiee S. \& Keyhani A. (2008). Energy Use and Economical Analysis of Potato Production in Iran A Case Study: Ardabil Province, Energy Conversion and Management 49(3):566-3570

Mrini M, Senhaji . \& Pimentel D. (2001). Energy Analysis of Sugarcane Production in Morocco. Environ, Dev Sustainability 3:109-126.

Özkan, B., Akçaöz, H. \& Fert, C. (2004). Energy InputOutput Analysis in Turkish Agriculture, Renewable Energy, 29(1): 39-51

Pringer, GJ. \& Steinberg, L. (2006). Reevaluation of Energy Use in Wheat Production in The United States. Journal of Industrial Ecology, 10:149-167

Rehman, H. \& Bashir F. (2015). Energy Consumption and Agriculture Sector in Middle Income Developing Countries: A Panel Data Analysis, Pakistan Journal of Social Sciences, 35(1):479-496.

Schneph, R. (2004). Energy Use in Agriculture: Background and Issues, CRS Report for Congress

Shrestha, DS. (1998). Energy Use Efficiency Indicator for Agriculture, erişim: 22.09.2019<http://www.usaskca/agriculture/caedac/ PDF/mcrae>. PDF, 10/10/2002.

Tatoğlu ,F.Y., 2012. İleri Panel Veri Analizi: Stata Uygulamal1, Beta, İstanbul.

Tsatsarelis, CA. (1991). Energy Requirements for Cotton Production in Central Greece. JAgric Eng Res, 50:239-246.

Zeren, F. \& Ergun, S. (2010). AB’ye Doğrudan Yabancı Yatırım Girişlerini Belirleyen Faktörler: Dinamik Panel Veri Analizi, İşletme ve Ekonomi Araştırmaları Dergisi, (1)4, 67-83

Zinck J. Berroterán J., Farshad A., Moamenı, A., Wokabi S. \& Ranst E. V. (2002). Approaches To Assessing Sustainable Agriculture, Ciencia del Suelo 20(2):5568. 